(c) American Dairy Science Association, 2005.

\title{
Protective Influence of Several Packaging Materials on Light Oxidation of Milk
}

\author{
F. Mestdagh, B. De Meulenaer, J. De Clippeleer, \\ F. Devlieghere, and A. Huyghebaert \\ Department of Food Safety and Food Quality, Ghent University, \\ Coupure Links 653, 9000 Ghent, Belgium
}

\begin{abstract}
Light-induced degradation reactions in milk create a serious problem for the dairy industry because of the development of off-flavors, the decrease in nutritional quality, and the severity and speed by which these phenomena develop. Packaging materials are essential to avoid this particular deterioration of milk. Therefore, efforts are being made to design protective polyethylene terephthalate (PET) packages. In the present study, a number of PET bottles were compared for their ability to avoid photo-oxidation in UHT semiskimmed milk. The milk was packed in 3 types of PET bottles: one transparent bottle provided with an active oxygen-binding inner layer, one bottle with perfect light barrier, and one transparent bottle provided with a UV-absorbing additive. During 2 storage experiments, running parallel to each other for 2 mo, chemical milk quality parameters such as fat oxidation, vitamin and protein degradation, oxygen consumption, and color change were monitored. A trained taste panel compared the sensory quality of the illuminated milk stored in these bottles, with milk perfectly protected against light and oxygen. In the first study, milk was continuously illuminated at room temperature. A comparison was made for milk under storage conditions that simulated those expected during display in retail and supermarkets. The results of the 2 shelflife studies showed that an adequate light barrier was apparently sufficient to avoid the light-induced oxidation of milk during extended storage. Oxygen barriers, on the other hand, did not provide a significant protection, nor did bottles with UV filter. If wavelengths detrimental to riboflavin were not completely excluded by the packaging material, incoming light could still give rise to photo degradation of milk. Accordingly, riboflavin and vitamin A were gradually degraded, milk fat was photo-oxidized, oxygen dissolved in the
\end{abstract}

Received June 2, 2004.

Accepted September 14, 2004.

Corresponding author: B. De Meulenaer; e-mail: Bruno. DeMeulenaer@UGent.be. milk was consumed, and the sensorial quality decreased significantly.

(Key words: light oxidation, off-flavor, ultra-high temperature milk, packaging)

Abbreviation key: DMDS = dimethyl disulfide, FID = flame ionization detector, PET = polyethylene terephthalate, PET-0 = PET-2 bottle protected from light, PET-1 = 3-layered (white-black-white) PET, PET-2 = transparent 3-layered PET with an active oxygen-binding inner layer, PET-3 = transparent monolayer PET provided with a UV-absorbing additive, $\mathbf{S P M E}=$ solid-phase microextraction, $\mathbf{T B A}=2$ thio-barbituric acid.

\section{INTRODUCTION}

As with many other foods, milk and dairy products are susceptible to oxidation. Dairy products in particular are very sensitive to light oxidation because of the presence of riboflavin (vitamin $\mathrm{B}_{2}$ ). This strong photosensitizer is able to absorb visible and UV light and transfer this energy into highly reactive forms of oxygen such as singlet oxygen (Min and Boff, 2002). These may, in turn, induce a cascade of oxidation reactions, leading finally to significant losses of valuable nutrients, such as vitamins (including vitamins $\mathrm{A}, \mathrm{B}_{2}, \mathrm{C}$, $\mathrm{D}$, and $\mathrm{E}$ ) and amino acids; to lipid oxidation; to discoloration; as well as to formation of strong off-flavors (Borle et al., 2001). Jung et al. (1998) suggested that dimethyl disulfide (DMDS) is formed by singlet oxygen oxidation of the amino acid methionine. In addition, typical secondary oxidation products, such as pentanal and hexanal, are formed during light-induced oxidation of unsaturated lipids in milk (Rysstad et al., 1998; Marsili, 1999). Particularly, all of these decomposition products have a very strong off-flavor with a low threshold value and are thought to be responsible for the development of light-induced off-flavor in milk and dairy products.

Consequently, control of the (photo) oxidation process is a prime matter of concern with regard to the quality of milk and dairy products. As a further conse- 
quence, the role of packaging technology to minimize the (photo) oxidative deterioration of these products becomes ever more important because of the growing trend to develop food products with a longer shelf-life. After all, by selection of the appropriate packaging material, a packed food can be properly protected toward both light and oxygen. The chemical inertness of polyethylene terephthalate (PET) coupled to its adequate gas barrier properties for retention of carbonation has made it particularly suitable for food packaging applications. Polyethylene terephthalate has been used in recent years as a very effective packaging material for carbonated beverages, edible oils, and other foods. Its use for milk packaging would help overcome problems that have accompanied other materials. Furthermore, PET is lightweight, not easily breakable, and is fully recyclable for both food and non-food applications. The contents of PET bottles can be easily poured, and an open bottle can be resealed, thus minimizing product recontamination and wastage (ILSI, 2000).

In view of the development of appropriate PET packaging for a whole range of dairy beverage products, the aim of this research was to explore the prolonged protective character of 3 new PET bottles against photo-oxidation. Because the shelf-life of an unopened UHT milk bottle is several months, this milk is, compared with other milk types (such as pasteurized milk), much more and much longer exposed to oxidation and deterioration processes during storage. To evaluate these long-lasting phenomena, UHT semiskimmed milk was chosen. During 2 storage experiments, different chemical and sensorial analysis techniques were used to measure the milk quality.

\section{MATERIALS AND METHODS}

\section{Milk Processing and Packaging}

Fresh full cream and skimmed milk were supplied by Olympia NV (Herfelingen, Belgium) and mixed together by MIK (Kruishoutem, Belgium) to adjust the fat content of the milk to approximately $1.5 \%$ (wt/wt). The final fat content turned out to be $1.30 \%$ (wt/wt) and was determined by the Röse-Gottlieb method (IDF Standard 1C, 1987). The milk was not fortified with additional nutrients (such as vitamins). At the Belgian Center for Agricultural Research (CLO, Melle, Belgium), the standardized semi-skimmed milk was indirectly UHT-sterilized using the APV Junior Twin UHT-Process Pilot Plant. Milk was preheated to $65^{\circ} \mathrm{C}$. Homogenization was done in 2 stages at $65^{\circ} \mathrm{C}$ and 20 MPa with an APV Gaulin model 53/21M3 homogenization apparatus. Subsequently, the milk was heated in an APV Junior Paraflow plate heat exchanger to the sterilization temperature of $140^{\circ} \mathrm{C}$ (5-s holding time). The milk was then cooled down in plate heat exchangers and stored at $4^{\circ} \mathrm{C}$ in stainless steel containers until packed.

The aseptic filling of the PET bottles was carried out in a sterilized room under laminar airflow. The semi-skimmed milk was manually packed in 3 different 1-L PET bottles: the 3-layered (white-black-white) bottle (PET-1) provided a perfect light barrier; the transparent 3-layered bottle with an active oxygenbinding inner layer (PET-2) present inside the bottle (composed of nylon with an oxygen scavenger) offered a perfect barrier against atmospheric oxygen diffusion into the bottle; and the transparent (PET-3) bottle was provided with a UV-absorbing additive. These bottles were previously sterilized by gamma irradiation at Isotron BV (Eden, the Netherlands). The filled bottles were manually closed with aluminum seals (Capsteril PAL811; Vaassen Flexible Packaging, the Netherlands), which were autoclaved at $121^{\circ} \mathrm{C}$ for $20 \mathrm{~min}$ prior to their use. These seals were carefully melted on the bottlenecks to obtain good sealing. Headspace volume varied between 20 and $50 \mathrm{~mL}$. During processing and packaging, milk illumination was prevented as much as possible by dimming the lights and putting the filled bottles immediately after sealing in cardboard boxes. During this filling process, milk samples were taken for a sterility test.

\section{Milk Storage}

All milk bottles were stored at room temperature (18 to $\left.25^{\circ} \mathrm{C}\right)$. Homogenous illumination $(2500 \mathrm{~lx})$ was obtained in a light cabinet using Philips TL-D 36W/ 830 fluorescent tubes, fixed $0.5 \mathrm{~m}$ above the bottles. The illumination intensity was measured at the level of the bottlenecks using a Lux meter (PAR-cell 532; 400 to $700 \mathrm{~nm}$, Skye Instruments) connected to a Multimeter (Hewlett Packard). To ensure even light distribution among the containers, the bottles were placed in random order. However, the reference milk (PET-0), not subjected to light oxidation, was packed in transparent PET-2 bottles, and was stored in the dark. Consequently, the milk packed in these bottles was both protected against light and against incoming oxygen.

Two types of storage experiments were conducted. In the first study (continuous illumination), the PET bottles, except PET-0, were continuously illuminated during a 2-mo period. During the first 3 wk of the second storage experiment (reality-simulating illumination), all milk bottles were stored in the dark, followed by a 13-d illumination storage (except for PET0 ). Thereafter, the bottles were again protected from 


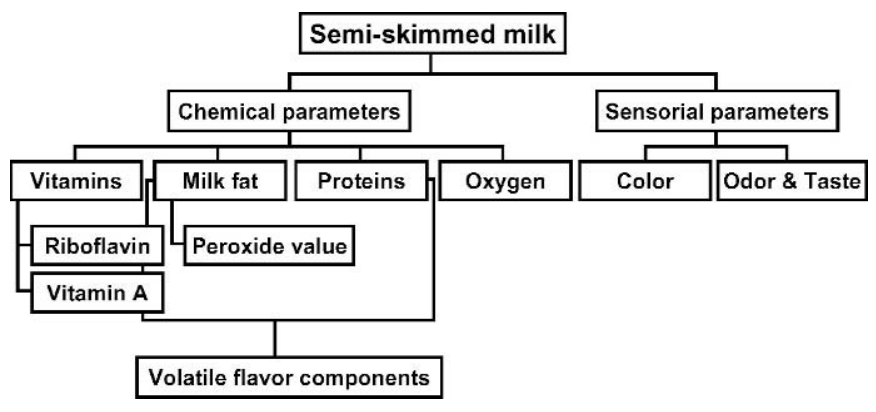

Figure 1. Schematic overview of the monitored quality parameters during storage experiments.

light. The latter study simulated those storage conditions expected during display in retail and supermarkets and later in consumers' houses. At various times, chemical and sensorial milk quality parameters, shown in Figure 1, were evaluated, using PET-0 as a reference. At each measuring point, $10 \mathrm{~L}$ of each bottle type were opened for sensory and chemical analysis.

\section{Measurement of the Light Transmittance of the PET Bottles}

The light transmittance of the different PET bottles was determined from 200 to $800 \mathrm{~nm}$ using a Varian Cary 50 Bio Spectrophotometer (Mulgrave Victoria, Australia). The measurements were carried out on a flat piece of packaging material, which just fit a quartz cuvette. The UV/Visible scan rate applied was 60 $\mathrm{nm} / \mathrm{min}$.

\section{Extraction of Milk Fat}

Milk fat was isolated using the BDI method (IDF Bulletin 265, 1991). An incomplete separation of the milk fat from the water fraction occurred in highly light-oxidized milk fat. To obtain an anhydrous fat extract from such fat-water samples, the samples were filtered through $595^{1 / 2}$ folded filters [internal diameter $(\varnothing)=125 \mathrm{~mm}$ (Schleicher \& Schuell, Germany)] filled with sodium sulfate (Chem-Lab, Belgium) as a desiccant. This filtration was performed at $60^{\circ} \mathrm{C}$ so that the fat did not congeal. The extracted fat was stored $\leq 1$ wk in the freezer at $-20^{\circ} \mathrm{C}$ until its use for the determination of the vitamin $\mathrm{A}$ and peroxide value contents.

\section{Vitamin $B_{2}$ (Riboflavin) Analysis}

Riboflavin was determined by combining the methods of Brubacher et al. (1986), Cooperman and Lopez (1991), and Kirk and Sawyer (1991). To avoid further light degradation during sample pretreatment, the samples were protected from light using aluminum foil. Protein-bound and/or phosphorylated riboflavin was extracted from each sample and converted to the free dissolved form by an acid and enzymatic hydrolysis. To perform this test, $50 \mathrm{~mL}$ of $0.2 \mathrm{~N}$ sulfuric acid (Chem-Lab) was added to $10 \mathrm{~g}$ of homogenized milk, followed by a 15 -min heating time in a boiling water bath. After cooling down and adjusting the $\mathrm{pH}$ to 4.5 with sodium acetate (Chem-Lab), $5 \mathrm{~mL}$ of a $10 \%$ Claradiastase multienzyme solution (Fluka, Switzerland) were added, followed by a 60- to 90-min incubation period in a $45^{\circ} \mathrm{C}$ water bath. To precipitate the proteins, the solutions were acidified with $4 \mathrm{~mL}$ of $2.5 \mathrm{M}$ sulfuric acid and heated for 15 min in a boiling water bath. Finally, the 100-mL solutions were filtered, and riboflavin was quantitatively measured using reversed-phase HPLC with fluorescence detection. The Gilson 122 HPLC system (Villiers-le-Bel, France) was composed of a Chrompack column packed with LiChrosorb RP-C18 (Varian; particle size, $10 \mathrm{~mm}$; $\varnothing$ internal, $4.6 \mathrm{~mm}$; $\varnothing$ outside, $6.34 \mathrm{~mm}$; length, $25 \mathrm{~cm}$ ), a Gilson 307 singular flow pump, and a fluorescence detector with a 150-W Xenon lamp. The fluorescence detection was programmed with an excitation wavelength of 450 $\mathrm{nm}$ and an emission wavelength of $530 \mathrm{~nm}$. The mobile phase consisted of acetonitrile (HPLC grade; Fisher Scientific, UK) and $\mathrm{H}_{2} \mathrm{O}$ (20:80), the flow rate was 1 $\mathrm{mL} / \mathrm{min}$, and the injection volume used was $20 \mu \mathrm{L}$. The riboflavin peaks were identified and quantified on the basis of riboflavin (Merck, Germany) standard solutions used as external standards.

\section{Vitamin A Analysis}

Five grams of anhydrous milk fat was saponified with $50 \mathrm{~mL}$ of $96 \%$ ethanol (Chem-Lab) and $10 \mathrm{~mL}$ of $50 \% \mathrm{wt} / \mathrm{vol} \mathrm{KOH}$ (Chem-Lab) for $30 \mathrm{~min}$ using a reflux condenser. To avoid possible oxidation, $10 \mathrm{~mL}$ of $20 \%$ wt/vol Na-ascorbate (UCB, Belgium) and $100 \mathrm{mg}$ of butyl hydroxytoluene (Acros Organics, Belgium) was added. Retinol (vitamin A alcohol) was further extracted with $80 \mathrm{~mL}$ of petroleum ether (Panreac Quimica, Spain) and $20 \mathrm{~mL}$ of $96 \%$ ethanol and twice with $40 \mathrm{~mL}$ of petroleum ether and $10 \mathrm{~mL}$ of $96 \%$ ethanol. All ether fractions were combined and washed 3 times with $40 \mathrm{~mL}$ of a $3 \% \mathrm{wt} / \mathrm{vol}$ alcoholic $\mathrm{KOH}$ solution and afterward with $40 \mathrm{~mL}$ of water until free of base. After evaporation of the ether fractions, vitamin A was determined by reverse-phase HPLC without isomer separation (IDF Standard 142, 1990). The Gilson HPLC system (Manometric model 805; Villiers-le-Bel) was composed of a Chrompack column packed with LiChrosorb RP-C18 (Varian; particle size, $10 \mathrm{~mm}$; $\varnothing$ internal, $4.6 \mathrm{~mm}$; $\varnothing$ outside, $6.35 \mathrm{~mm}$; length, $25 \mathrm{~cm}$ ), a Gilson 
305 singular flow pump, and a Gilson 118 UV detector (detection at $325 \mathrm{~nm}$ ). The mobile phase consisted of methanol (HPLC grade; Fisher Chemicals, UK) and $\mathrm{H}_{2} \mathrm{O}$ (95:5), the flow rate was $1.2 \mathrm{~mL} / \mathrm{min}$, and the injection volume used was $20 \mu \mathrm{L}$. The vitamin A peaks were identified and quantified on the basis of vitamin A (retinyl acetate stock solution; Merck) standard solutions used as external standards.

\section{Determination of the Fat Oxidation}

The intention was to measure both primary and secondary fat oxidation products. Primary oxidation compounds were spectrophotometrically quantified in anhydrous milk fat using the peroxide value determination method (IDF Standard 74A, 1991) entailing reaction of peroxides with iron(II) chloride and ammonium thiocyanate, followed by absorbance measurements at $500 \mathrm{~nm}$ after reaction for exactly $5 \mathrm{~min}$, recording the red iron(III) thiocyanate complex. The peroxide values were obtained using a standard curve based on $\mathrm{H}_{2} \mathrm{O}_{2}$. Sample light exposure was avoided as much as possible. In an attempt to determine the secondary oxidation products responsible for off-flavor in light-oxidized milk, 2 thiobarbituric acid (TBA) methods (Sidwell et al., 1954; King, 1962) were carried out on milk and milk fat, respectively.

\section{Headspace Analysis Using Gas Chromatography}

To analyze the undesirable volatile compounds resulting from light-induced oxidation of milk (pentanal, hexanal, and dimethyl disulfide), the solid-phase microextraction (SPME) adsorption procedure of Marsili (1999) was tested. Briefly, $3 \mathrm{~g}$ of milk sample and the internal standard (4-methyl-2-pentanone, spectrophotometric grade 99.5\%; Acros Organics) were weighed and sealed in a $9-\mathrm{mL}$ vial. Subsequently, the SPME fiber (75- $\mu \mathrm{m}$ Carboxen/PDMS; Supelco, Bellefonte, PA) was inserted into the headspace of the vial for 15 min at $45^{\circ} \mathrm{C}$. Next, the fiber was manually inserted into a Varian CP-3800 gas chromatography apparatus (see subsequent). In addition to the static headspace analysis, the following dynamic headspace analysis was implemented. Five hundred milliliters of semiskimmed milk was poured into a sealable 1-L glass Erlenmeyer flask and placed in a hot water bath $\left(65^{\circ} \mathrm{C}\right)$; 4-methyl-2-pentanone, concentration $10 \mathrm{ng} /$ $\mathrm{mL}$, was used as an internal standard. To facilitate the extraction of the volatile compounds, $50 \mathrm{~g}$ of sodium sulfate (Chem-Lab) was added. A fixed volume $(1 \mathrm{~L})$ of He gas (flow, $0.1 \mathrm{~L} / \mathrm{min}$ ) was flushed through the Erlenmeyer flask headspace to transport the volatile compounds in the gas phase through a clean Tenax tube, on which these compounds were absorbed (Barcarolo et al., 1996). The Tenax tube, a glass inlet liner (Supelco, for ATAS OPTIC 2 High Volume Injector) with fritted bottom, contained $100 \mathrm{mg}$ of Tenax GR 35-60 (Alltech, Deerfield, IL) and was closed with a small amount of inert glass wool. The different compounds, adsorbed on Tenax, were analyzed on a gas chromatography flame ionization detection (FID) system using a Varian CP-3800 gas chromatography apparatus with an ATAS OPTIC 2 to 200 Programmable Temperature Evaporation injector, a Varian CP-Wax 52 CB column (T666 polyethylene glycol; $\varnothing$ internal, $0.53 \mathrm{~mm}$; length, $50 \mathrm{~m}$; film thickness, $2 \mathrm{~mm}$ ), and a FID set at $250^{\circ} \mathrm{C}$. The flow rate of air and $\mathrm{H}_{2}$ were, respectively, 300 and $30 \mathrm{~mL} / \mathrm{min}$. The initial injector temperature was $40^{\circ} \mathrm{C}$, with an overpressure of 41.4 $\mathrm{kPa}$. After the start of the analysis, the injector was quickly heated with $16^{\circ} \mathrm{C} / \mathrm{s}$ up to $230^{\circ} \mathrm{C}$. The injection mode was splitless, and the splitless time was 2 min; thereafter, the split was $1 / 1$. Helium was used as a carrier gas with a flow rate of $6 \mathrm{~mL} / \mathrm{min}$. The column temperature was initially $40^{\circ} \mathrm{C}$ for $1 \mathrm{~min}$, heated to $82^{\circ} \mathrm{C}$ at a rate of $2^{\circ} \mathrm{C} / \mathrm{min}$, and held at $82^{\circ} \mathrm{C}$ for $1 \mathrm{~min}$, heated to $225^{\circ} \mathrm{C}$ at a rate of $30^{\circ} \mathrm{C} / \mathrm{min}$, and held at $225^{\circ} \mathrm{C}$ for $2 \mathrm{~min}$. Peak identification was done using different standard solutions $(100 \mu \mathrm{g} / \mathrm{mL})$ of pure 4methyl-2-pentanone, pentanal, hexanal, and DMDS (Acros Organics). Calibration was based on peak area results using the method of additions technique and an internal standard in a matrix of unilluminated skimmed milk powder dissolved in $\mathrm{H}_{2} \mathrm{O}(10 \% \mathrm{wt} / \mathrm{vol})$.

\section{Determination of Oxygen}

The amount of oxygen dissolved in the semiskimmed milk was determined using the Orbisphere method (Geneva, Switzerland), according to the manufacturer's instructions.

\section{Sensory Analysis}

Olfaction and taste perception. A sensory panel, consisting of students and faculty members, was selected and trained to distinguish the typical light-induced milk odor and taste. Persons with the most sensitive smell organs and taste papillae were retained. To evaluate the sensorial changes during the 2 illumination studies, a triangle test was used (Parolari, 1996). In each test, the reference milk (PET-0) was compared with an illuminated milk sample, by odor and by taste. Unsalted crackers were supplied to cleanse the palate between 2 tests. Statistical analysis of the obtained data was performed according to Parolari (1996). The microbial quality of the samples was 
monitored measuring the product $\mathrm{pH}$ and establishing eventual gas production.

Color measurement. In function of the illumination time, color changes were evaluated using a portable spectrophotometer (Minolta CM2500d, Japan) and expressed in the $\mathrm{L}^{*} \mathrm{a} * \mathrm{~b}^{*}$ color space. Each milk sample was poured into a 2 -cm deep plastic petri dish to prevent color interference of underlying tabletop. The brimful dish was then closed, avoiding air bubbles to be included under the cover. The measurement was performed by placing the instrument viewing port on the cover. To exclude variable cover surface conditions, the specular reflectance was included in the color measurement. The following measurement conditions were applied: UV, $100 \%$; standard illuminant, D65; color temperature, $6504 \mathrm{~K}$; observer angle, $10^{\circ}$; and delay time, $0.1 \mathrm{~s}$. Prior to every series of color measurements, the instrument was subjected to a white calibration. Each measurement was repeated 3 times.

\section{Selection of Relevant Parameters}

During preliminary experiments, some analytical tools to assess the light-induced changes in milk were evaluated, selected, optimized, and finally implemented in the 2 illumination studies.

Determination of fat oxidation. To determine the secondary oxidation products in the milk, 2 different thiobarbituric acid methods were tested. Using the method of Sidwell et al. (1954), no increase in TBA values was noticed during continuous light exposure of milk. No relationship was found between light oxidation of milk fat and expected formation of the chromogen. Applying the King (1962) method, initially there was no absorbance peak at $532 \mathrm{~nm}$ upon light exposure. With this method, no distinction could be made between an unexposed milk sample and an illuminated milk sample, with distinct light-oxidative offflavor (after a 30-h UV light treatment). Moreover, no reproducible measurements could be made. Changing the incubation temperature from 60 to $100^{\circ} \mathrm{C}$ or replacing the 2-thiobarbituric acid solvent from ethanol to acetic acid [as in the method of Sidwell et al. (1954)] did not yield satisfactory results. A possible explanation for this could be found in the fact that, during the analytical procedure, fat can be further oxidized because of oxygen present in the reagents. Results were not consistent with those of Cladman et al. (1998) and Moyssiadi et al. (2004), who could clearly distinguish TBA values of pasteurized milk, packed in different pigmented high density polyethylene, PET, and cardboard packages during a 7-d illumination study. On the other hand, Barrefors et al. (1995) stated that the TBA test results are poorly correlated with taste

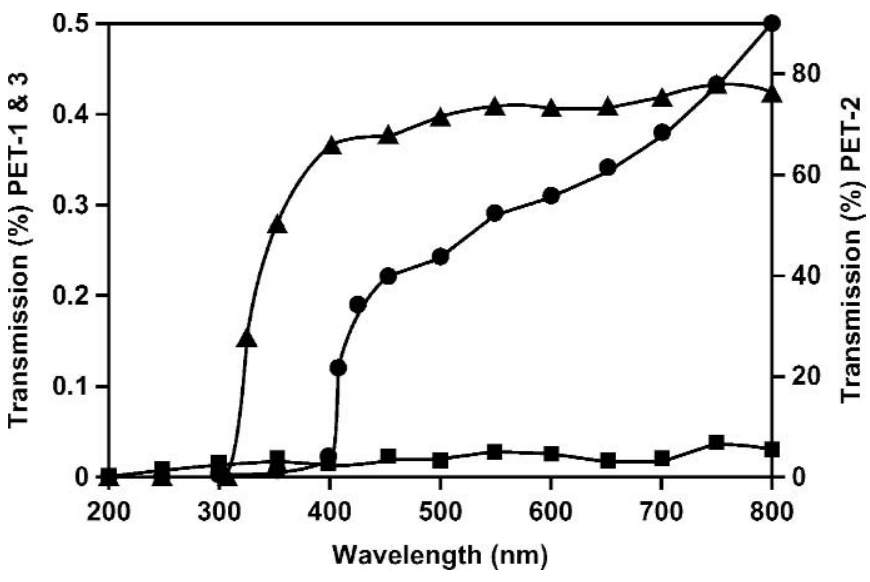

Figure 2. Light transmission spectra of PET-1 [ $\mathbf{\square}$; 3-layered (white-black-white) polyethylene terephthalate (PET)] , PET-2 ( $\mathbf{\Delta}$; transparent 3-layered PET with an active oxygen-binding inner layer), and PET-3 ( ; transparent monolayer PET provided with UVabsorbing additive).

panel scores. Moreover, these results appeared to be less sensitive to low concentrations of carbonyl compounds. According to Rysstad et al. (1998), weak oxidation defects, which could be detected by sensory tests, were not necessarily detected by the TBA analysis. As a consequence, those authors preferred to analyze the volatile oxidation products by gas chromatographic headspace analysis. On the other hand, the peroxide value, which determines primary oxidation products, gave clear and reproducible results concerning light oxidation of the milk fat.

Headspace analysis. The SPME gas chromatography-MS method, proposed by Marsili (1999), did not appear to be sensitive enough in the applied analytical configuration (SPME gas chromatography-FID). Concentrations of hexanal, pentanal, and DMDS in milk could not be detected below $30 \mathrm{ng} / \mathrm{mL}$. At this concentration level, the light-induced off-flavor was clearly present upon milk tasting. Doubling the SPME adsorption time and raising the absorption temperature to $65^{\circ} \mathrm{C}$ did not contribute to more sensitive results. Therefore, preference was given to dynamic headspace analysis, where hexanal, pentanal, and DMDS could be detected from $1 \mathrm{ng} / \mathrm{mL}$.

\section{RESULTS AND DISCUSSION}

\section{Measurement of the Light Transmittance of the PET Bottles}

According to the International Dairy Federation, the light transmittance of a package may not exceed $2 \%$ at $400 \mathrm{~nm}$ and $8 \%$ at $500 \mathrm{~nm}$ (Mottar, 1986) to protect foodstuffs sufficiently against light oxidation. However, as shown in Figure 2, PET-2 presented almost 
A

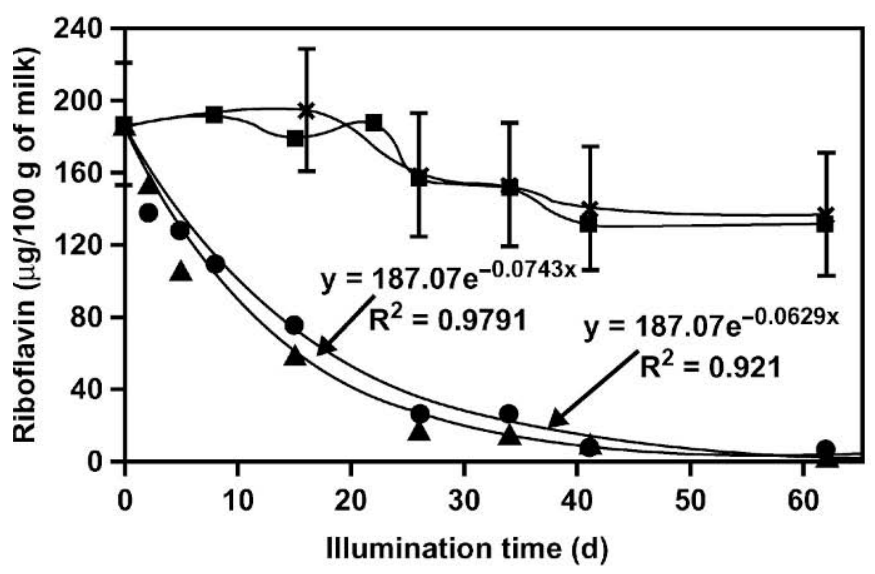

B

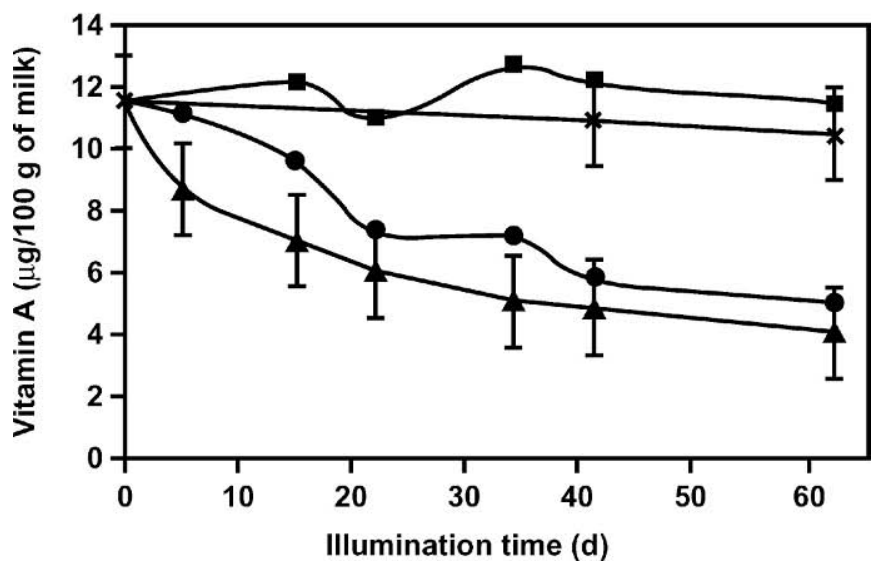

Figure 3. A) Riboflavin and B) vitamin A concentration in milk stored in PET-0 [X; 3-layered polyethylene terephthalate (PET) with an active oxygen-binding inner layer], PET-1 [ $\mathbf{\square}$; 3-layered (whiteblack-white) PET], PET-2 ( $\boldsymbol{\Delta}$; transparent 3-layered PET with an active oxygen-binding inner layer), and PET-3 (- transparent monolayer PET provided with UV-absorbing additive) during continuous illumination.

complete light transmittance (70 to $80 \%$ ) from 800 to about $310 \mathrm{~nm}$. The PET-3 revealed only 0.5 to $0.2 \%$ transmittance from 800 to about $400 \mathrm{~nm}$. The fall of the transmittance to nearly zero at approximately 400 $\mathrm{nm}$ was very significant and proved the effectiveness of the UV-absorbing additive.

\section{Results of the Continuous and Reality-Simulating Illumination Studies}

Riboflavin analysis. The changes in concentration of riboflavin with continuous illumination time are shown in Figure 3a. To keep a clear view on the results, the $95 \%$ confidence levels are only indicated for the PET-0 bottles. Riboflavin in milk packed in PET-2 and
PET-3 gradually degraded as a result of the continuous illuminated storage. No significant difference could be observed between the PET-2 and PET-3 curve. After 41 $\mathrm{d}$ of light exposure, the photosensitizer had undergone almost complete photolysis. As stated earlier in the literature (Allen and Parks, 1979), this degradation process can be described well with first-order reaction kinetics. As shown in Figure 3a, the reaction constant is about $0.07 / \mathrm{d}$. On the other hand, it is difficult to compare this reaction constant with other values published in the literature. In addition to the packaging material, many other factors may influence the degradation kinetics of riboflavin, such as the (distance from the) light source, wavelength intensity, exposure time and temperature, milk heat treatment, and homogenization (Bekbölet, 1990; Saidi and Warthesen, 1995).

In the reality-simulating illumination of PET-2 and PET-3 (results not shown), the decrease in riboflavin was initiated only after the start of the light exposure at $\mathrm{d} 20$. The degradation patterns and kinetics observed during the $13 \mathrm{~d}$ of light exposure were similar to the continuous illumination study, with reaction constants of 0.075 and $0.050 / d$ for PET-2 and PET-3, respectively. After the first $7 \mathrm{~d}$ of dark storage subsequent to illumination, no further decrease in riboflavin content was observed because of the absence of light.

The results from both studies show clearly that PET2 and PET-3 did not offer sufficient protection for the light-induced degradation of the vitamin. According to Borle et al. (2001), the third absorption band of riboflavin ( 430 to $460 \mathrm{~nm}$ ) is the main band responsible for the photo-oxidation of food, especially in milk and dairy products. As PET-2 and PET-3 did not sufficiently filter out this band (Figure 2), it is obvious that riboflavin could still give rise to photo degradation reactions in these bottles. In this region, PET-3 protected much more against light exposure than PET-2, but apparently, even a small amount of radiation is enough to initialize the degradation processes. On the other hand, both during the continuous- and realitysimulating light exposure, the milk in PET-1 as well as in PET-0 maintained its riboflavin content at the original level for an extended period, after which only a slight decrease was observed.

Vitamin A analysis. Vitamin A in milk packed in PET-2 and PET-3 gradually degraded as a result of the continuous-illuminated storage (Figure 3b). Onehalf of the original vitamin A content in PET-2 had undergone photolysis after only $22 \mathrm{~d}$ of light exposure, compared with $41 \mathrm{~d}$ for PET-3. During further light exposure, vitamin A in PET-2 and PET-3 finally dropped to 29 and $39 \%$ (no significant difference) of its original content, respectively. 
In the reality-simulating illumination of PET-2 and PET-3 (results not shown), the decrease in vitamin A was initiated only after the start of the light exposure at $\mathrm{d} 20$, as was already observed for riboflavin. At the end of illumination, the vitamin A content in PET-2 and PET-3, respectively, dropped to 50 and $70 \%$ of its original content. From the time the light exposure was blocked again, the vitamin A content of the milk packed in the 2 bottles dropped only slightly further.

Both during the continuous- and reality-simulating light exposure, the milk in PET-1 as well as in PET0 maintained its vitamin A content at the original level for an extended period, after which a slight decrease was observed. It is clear that PET-2 and PET-3 did not offer sufficient protection for the light-induced degradation of vitamin A in semi-skimmed milk. According to Fanelli et al. (1985), vitamin A is rapidly destroyed by wavelengths below $415 \mathrm{~nm}$. The PET-2 and PET-3 did not give adequate protection in this spectral region (Figure 2). Cladman et al. (1998) postulated that PET, which absorbs a minimum of $95 \%$ of UV radiation, is effective in preventing vitamin A degradation during an 18-d storage period. Present results show that this $95 \%$ UV protection is not sufficient to prevent vitamin degradation during a more prolonged light exposure, as in the case of PET-3. In addition, it appears that a certain portion of vitamin $\mathrm{A}$ is lost rapidly upon light exposure, with the remaining portion being resistant to further destruction, which is in accordance with deMan (1980).

Determination of the fat oxidation. The evolution of the peroxide value, expressed as the number of milliequivalents of oxygen per kilogram of anhydrous milk fat during the continuous- and reality-simulating illumination studies is shown in Figure 4. The peroxide value in milk packed in PET-2 and PET-3 gradually increased as a result of the continuous illuminated storage (Figure 4a). However, the peroxide value for PET-2 samples markedly increased to a greater extent than for PET-3. Apparently, the UV filter had a significant influence on fat oxidation during prolonged illumination, confirming the results obtained by Cladman et al. (1998). For both PET-2 and PET-3, the peroxide values stagnated or even declined, after an initial rise. Obviously, at later stages of milk fat oxidation, the rate of hydroperoxide decomposition to secondary oxidation products exceeded their rate of formation.

In the reality-simulating illumination of PET-2 and PET-3 (Figure 4b), the gradual increase in peroxide value was initiated only after the start of the light exposure at d 20. In contrast to the first study, the peroxide value of PET-3 increased to a somewhat greater extent in contrast with PET-2, which cannot
A

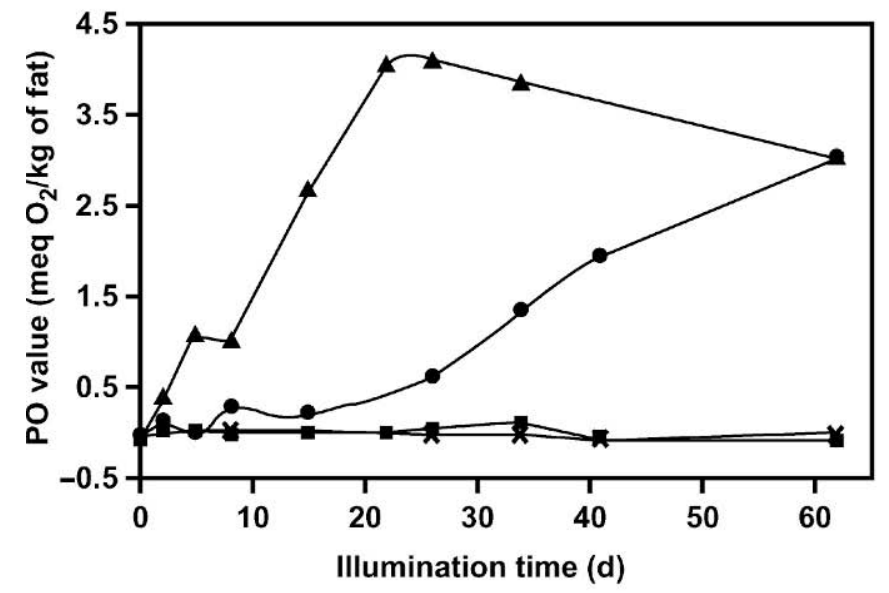

B

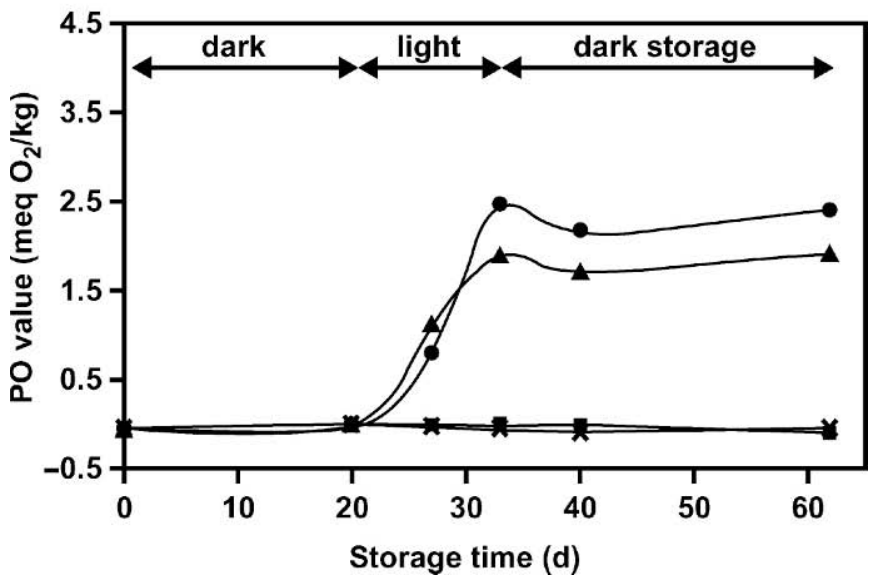

Figure 4. Peroxide (PO) value in milk fat stored in in PET-0 [X; 3-layered polyethylene terephthalate (PET) with an active oxygenbinding inner layer], PET-1 [ $\mathbf{0}$; 3-layered (white-black-white) PET], PET-2 ( $\Delta$; transparent 3-layered PET with an active oxygen-binding inner layer), and PET-3 (- transparent monolayer PET provided with UV-absorbing additive) during continuous illumination (A) and reality-simulating illumination $(\mathrm{B})$.

be properly explained. After storing the samples back in the dark, the peroxide value both for PET-2 and PET-3 remained at an elevated level.

It seems again that both PET-2 and PET-3 did not offer sufficient protection for the light-induced degradation of semi-skimmed milk fat. Even though, the UV-absorbing additive in PET-3 provided significant protection during prolonged illumination, compared with the PET-2 bottles. On the other hand, no fat oxidation could be detected in the milk packed in the PET-0 as well as in PET-1, as the peroxide value remained zero during both light exposure studies. 
A
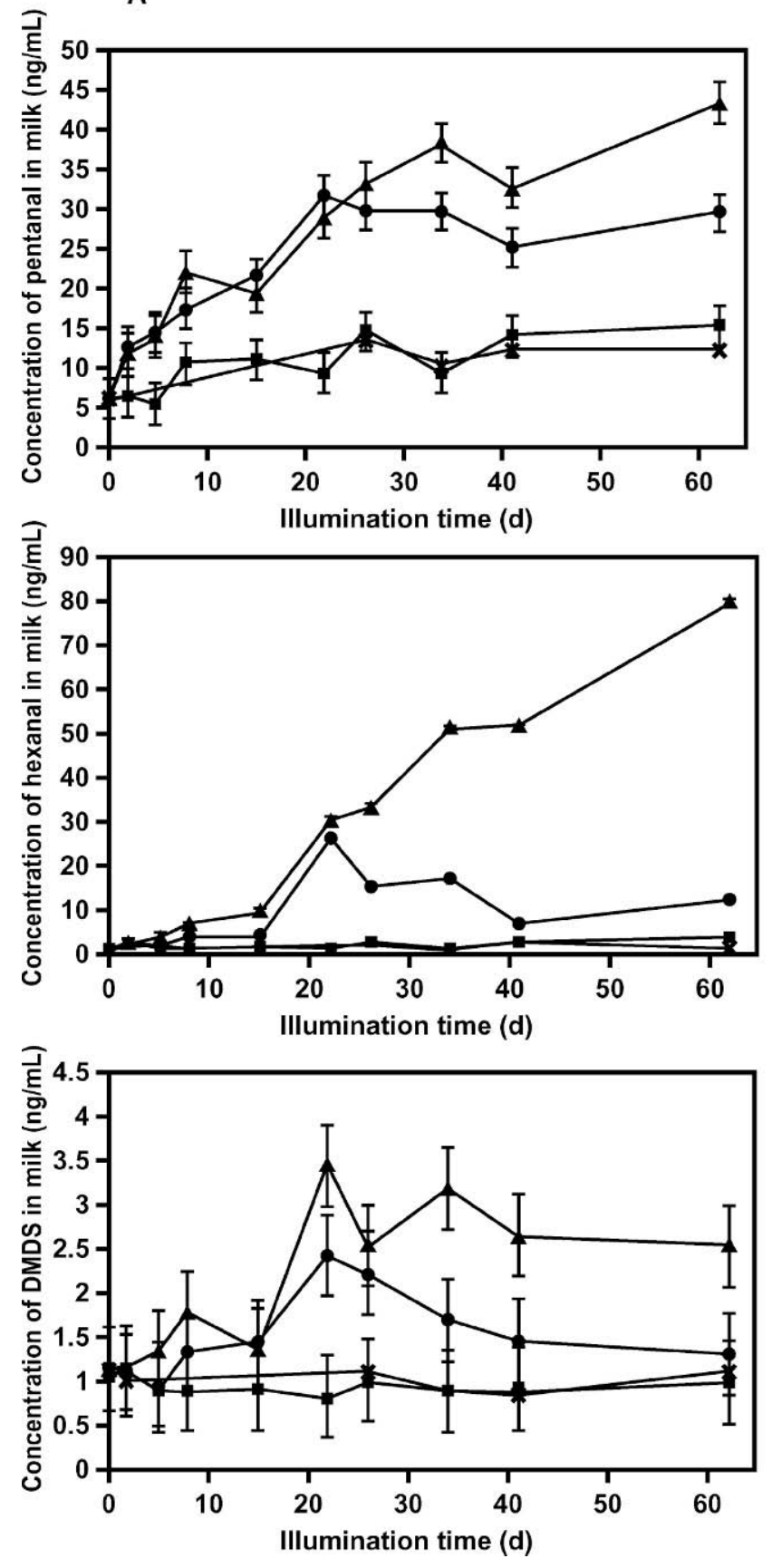

B
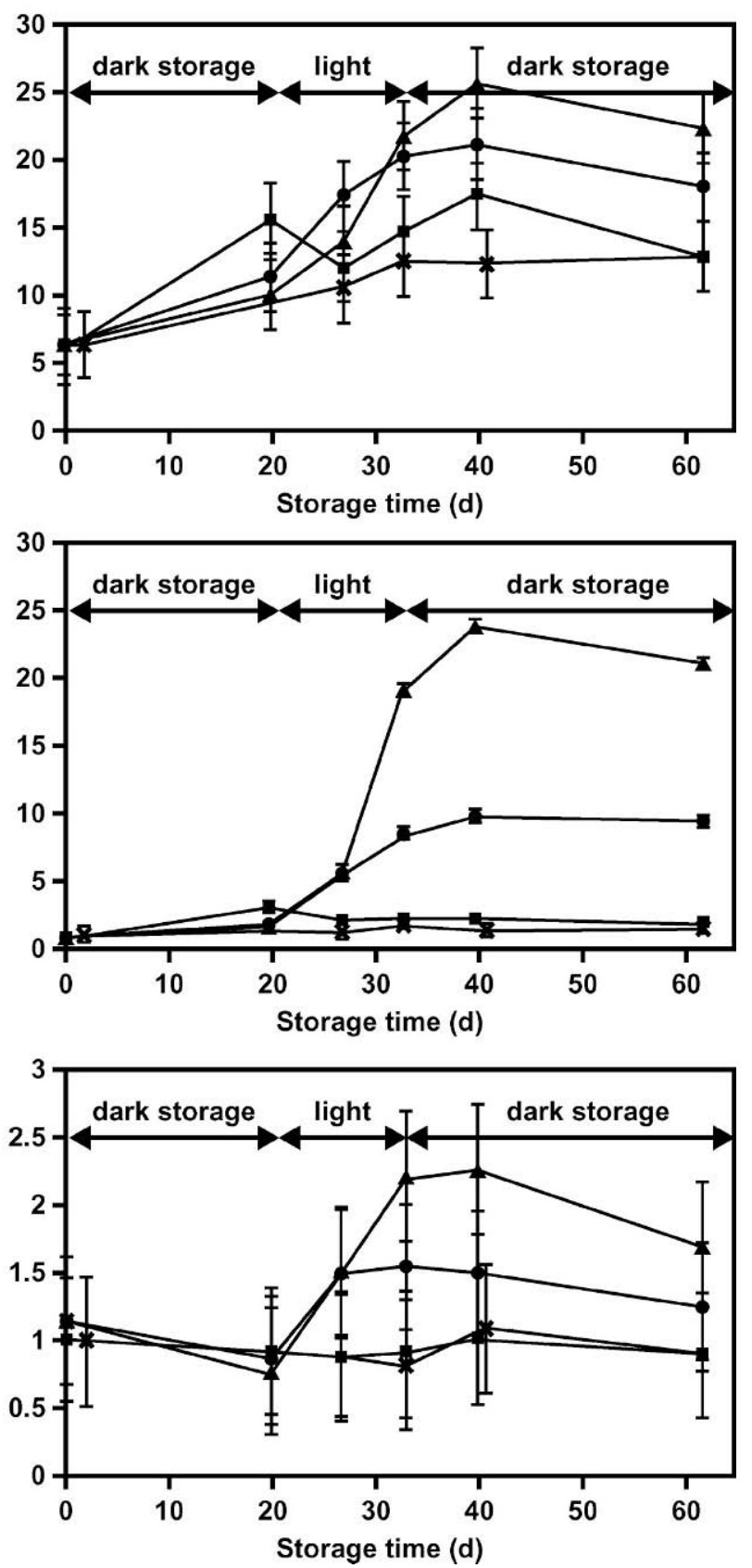

Figure 5. Changes in concentrations of pentanal, hexanal, and dimethyl disulfide(DMDS) in milk stored in PET-0 [X; 3-layered polyethylene terephthalate (PET) with an active oxygen-binding inner layer], PET-1 [ $\square$; 3-layered (white-black-white) PET], PET-2 (ム; transparent 3layered PET with an active oxygen-binding inner layer), and PET-3 (-; transparent monolayer PET provided with UV-absorbing additive) during continuous illumination (A) and reality-simulating illumination (B).

\section{Headspace Analysis Using Gas Chromatography}

Changes in concentration of pentanal, hexanal, and DMDS with the continuous- and reality-simulating illumination times are shown in Figure 5 (with the corresponding $95 \%$ confidence levels).
Upon being exposed to continuous light (Figure 5a), the concentrations of pentanal, hexanal, and DMDS increased as a function of the storage time in PET2 and PET-3. During the first $22 \mathrm{~d}$ of storage, the concentration of the different headspace compounds studied showed a similar enhancement in both bottle 
types (PET-2 and PET-3). These results are not in concordance with the evolution of the peroxide values. Apparently, no direct link could be made between peroxide values and volatile secondary oxidation products. However, from d 22, the pentanal, hexanal, and DMDS concentrations in PET-3 declined and stagnated, whereas for PET-2, the concentrations of these oxidation products at $\mathrm{d} 22$ further increased. Accordingly, a significant difference in pentanal, DMDS, and mainly hexanal concentration was observed between PET-2 and PET-3. A further oxidation of hexanal into its corresponding (and not measured) carbonic acid (caproic acid) could be an explanation for this decline. Dimethyl disulfide was present in smaller amounts.

In the reality-simulating illumination experiment (Figure 5b), oxidation products were not formed in the first stage of storage. From the moment samples were illuminated, concentrations of the 3 compounds increased as a function of time in a comparable way as in the first storage experiment with continuous illumination. However, it was noticed that, upon a short illumination of both PET-2 and PET-3, the increase of hexanal concentrations in PET-2 was significantly higher than in PET-3 bottles. Pentanal and DMDS concentrations did significantly increase for only the PET-2 bottles. Also in PET-3, these 2 compounds increased, although not significantly. When the samples were removed from light and stored in the dark again, all 3 product concentrations decreased or stagnated. Mehta and Bassette (1979) concluded that the oxidation reaction rate was not maintained by a process of auto-oxidation. The reaction was apparently photocatalyzed and required a constant source of radiant energy to be maintained.

From the results obtained, it could be concluded that PET-2 and PET-3 did not offer sufficient protection against the light-induced fat oxidation and protein degradation in semi-skimmed milk, as was demonstrated by the production of undesirable volatile compounds. On the other hand, Van Aardt et al. (2001) found lower oxidation off-flavor in PET with UV block compared with glass and clear PET bottles during an 18-d illumination study. Apparently, this partial protection against photo oxidation is not sufficient for longer storage periods, as was in this study. On the other hand, milk provided with an adequate light barrier, respectively, PET-1, and absence of light for PET0 , maintained its pentanal, hexanal, and DMDS concentrations at the original low level for an extended period, indicating an absence of light-induced fat oxidation and protein degradation.

\section{Determination of Oxygen}

The dissolved $\mathrm{O}_{2}$ concentration at the beginning of both illumination experiments was about $6 \mathrm{ppm}$, a

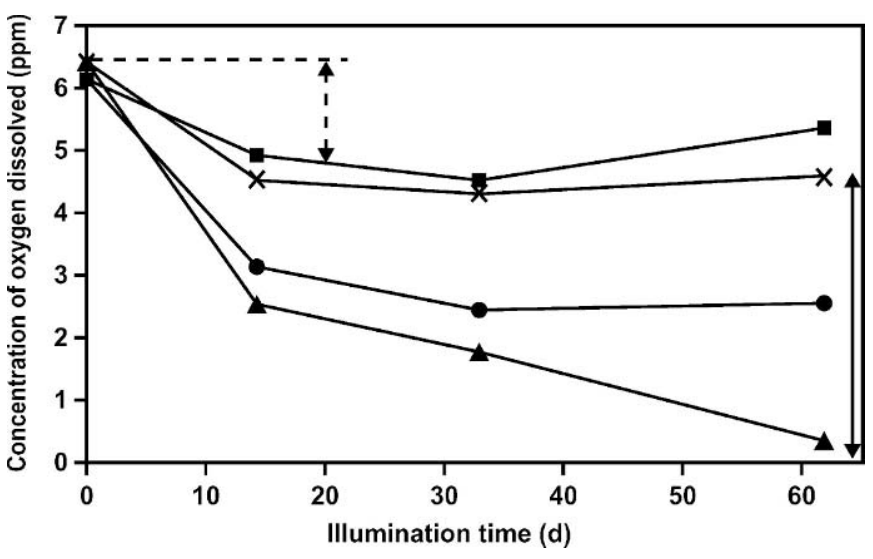

Figure 6. Concentration of dissolved oxygen in milk stored in PET-0 [X; 3-layered polyethylene terephthalate (PET) with an active oxygen-binding inner layer], PET-1 [ロ; 3-layered (white-black-white) PET], PET-2 ( $\mathbf{\Delta}$; transparent 3-layered PET with an active oxygenbinding inner layer), and PET-3 (-; transparent monolayer PET provided with UV-absorbing additive) during continuous illumination.

rather high concentration probably because of the sufficient amount of oxygen present in the headspace of the bottles. Upon continuous light exposure (Figure 6 ), the concentration decreased as a function of the storage time in PET-2 and PET-3. This decline was most explicit for PET-2. Because PET-2 was provided with an $\mathrm{O}_{2}$ barrier, and because PET-0 was not illuminated, the difference in dissolved $\mathrm{O}_{2}$ concentration between PET-2 and the corresponding unilluminated PET- 0 can be considered as a measure for the $\mathrm{O}_{2}$ consumption in light-induced oxidation and is indicated by the solid double arrow. This amounted to approximately $4 \mathrm{ppm} \mathrm{O}_{2}$ after $60 \mathrm{~d}$ of continuous illumination. It should be noted, however, that the decrease in dissolved oxygen concentration for PET-2 can be ascribed to both the $\mathrm{O}_{2}$ consumption during light-induced oxidation and to the scavenging of $\mathrm{O}_{2}$ by the active nylon inner layer, which appeared to be relatively restricted. Namely, after $62 \mathrm{~d}$, still $4.5 \mathrm{ppm}$ oxygen (from the 6 ppm initially) was present in the PET-0 bottle, and thus not bound on the nylon inner layer. Consequently, this amount of oxygen was still available for oxidation reactions. An explanation of this large residual amount of oxygen could be found in the fact that a large quantity of oxygen was still present in the headspace of the bottles and could diffuse into the milk during storage. Thus, the PET-2 bottles could not sufficiently remove oxygen (present in the bottle) to avoid lightinduced oxidation in the milk. An eventual relationship between the oxygen-binding capacities of PET bottles and the light-oxidation process could not be proven. To remove this in-bottle oxygen supply during future storage studies, the headspace should prefera- 
bly be flushed with nitrogen. In comparison with PET2 , the dissolved oxygen concentration in PET-3 decreased to a lesser extent. Two reasons can cause this difference: the UV filter in PET-3 inhibits somewhat the light-induced oxidation processes (and thus oxygen consumption), as can also be concluded out of the peroxide values (Figure 4), or the ingress of atmospheric oxygen into the PET-3 bottle is higher than in the PET-2 bottle. Both for PET-1 and PET-0, only a slight decrease of the initial dissolved $\mathrm{O}_{2}$ concentration was noticed. For PET-1 this reduction is indicated with a dashed double arrow and can be explained as the $\mathrm{O}_{2}$ consumption in oxidation processes, which should not be light-induced but spontaneously occurring. Of course, this $\mathrm{O}_{2}$ consumption is partially compensated by the limited oxygen ingress in the PET bottle.

The $\mathrm{O}_{2}$ migration from the outside into the PET-3 milk bottle was probably partially negating the $\mathrm{O}_{2}$ consumption during light-induced oxidation and could explain the slower decrease in dissolved $\mathrm{O}_{2}$ concentration for this bottle.

In the reality-simulating illumination study (results not shown), comparable results were obtained during light treatment. Because of diffusion of atmospheric oxygen into the PET-1 and PET-3 bottles, the observed oxygen concentrations increased somewhat during prolonged dark storage. The dissolved oxygen in PET2 gradually decreased in the dark storage (after illumination), because of continuing oxidation processes and because of the oxygen-binding capacity of this bottle type.

\section{Sensory Analysis}

Olfaction and taste perception. Results from both studies indicated that already after $2 \mathrm{~d}$ of illumination, PET-2 and PET-3 tasted and smelled significantly different $(P<0.05)$ from the reference bottle (PET-0). Chapman et al. (2002) also proved that trained panelists could detect light-oxidized defects in milk packed in light-transmissible high density polyethylene plastic containers exposed to light (2000 lx; $6^{\circ} \mathrm{C}$ ) after only 15 to $30 \mathrm{~min}$. On the other hand, no differences could be detected during the first stage of dark storage in the reality-simulating illumination study. Although pentanal and DMDS did not increase significantly during the headspace analysis in PET-3, the taste panel could clearly distinguish the milk offflavor in these bottles. Apparently, the human papillae proved their superior sensitivity, compared with the gas chromatographic analysis method. Light-activated flavor did not disappear when the milk bottles were again stored in the dark. The effectiveness of the light barrier against light-induced off-flavor was again
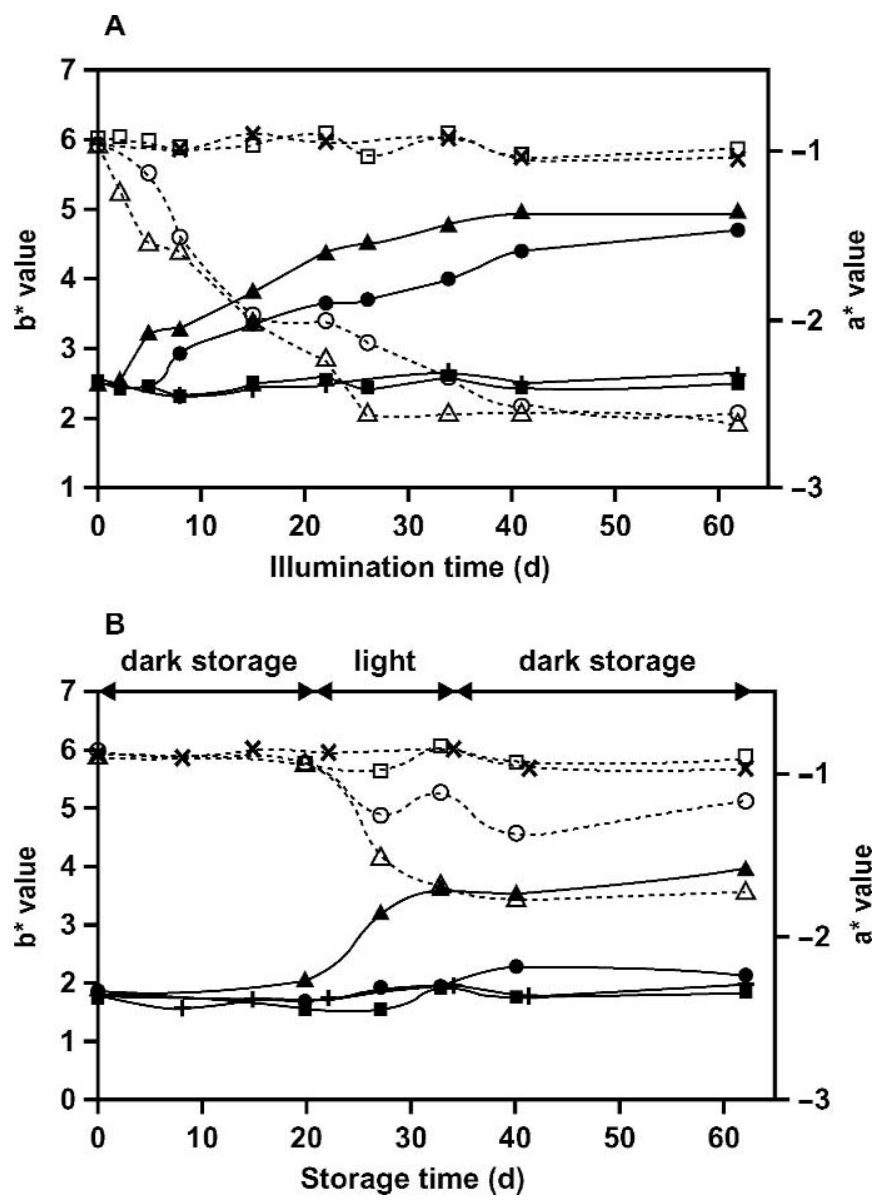

Figure 7. Changes in $a^{*} / b^{*}$ value of milk stored in PET-0 [3layered polyethylene terephthalate (PET) with an active oxygen-binding inner layer $(+/ \mathrm{X})$ ], PET-1 [3-layered (white-black-white) PET (ם/ $\square)$ ], PET-2 [transparent 3-layered PET with an active oxygen-binding inner layer $(\mathbf{\Delta} / \triangle)$ ], and PET-3 [transparent monolayer PET provided with UV-absorbing additive $(/ / \bigcirc)$ ] during continuous illumination (A) and reality-simulating illumination (B). The continuous lines connect the $a^{*}$ values; dotted lines connect the $b^{*}$ values.

illustrated, as milk in PET-1 bottles could not be differentiated from the reference during the whole storage period. Oxygen and UV barriers could not protect milk against the development of light-induced off-flavors.

Color measurement. Upon light exposure, the a* value gradually increased as a function of storage. The $b^{*}$ value, however, decreased as a function of the storage time in the milk samples, which were not fully protected from light, specifically PET-2 and PET-3 (Figure 7). This was, in both studies, most explicit for PET-2. When PET-2 and PET-3 were again stored in the dark, the $a^{*}$ and $b^{*}$ values stagnated. For both studies, the $\mathrm{L}^{*}$ (lightness) value was not influenced by both illumination conditions for all PET bottles.

Because a positive $b^{*}$ value indicates the yellow direction, a continuous decrease in $b^{*}$ value during illu- 
mination stands for a decrease in yellow color. As described in the literature by Toba et al. (1980), Bosset et al. (1994), and Lee et al. (1998), this color change is probably caused by the simultaneous degradation of the yellowish, green-colored riboflavin, $\beta$-carotene, and vitamin A molecules, as observed in the riboflavin and vitamin A content of milk packed in PET-2 and PET-3 (Figure 3). On the other hand, $+a^{*}$ indicates the red direction; accordingly, an $a^{*}$ increase stands for an increase in red color. Possibly, the browning during degradation of tryptophan and tyrosine could cause this change upon light exposure, as described by Toba et al. (1980). During both illumination studies, the milk packed in PET-1 and PET-0 maintained its $\mathrm{b}^{*}$ and $\mathrm{a}^{*}$ values at the original level throughout the storage time.

\section{CONCLUSIONS}

Light-induced milk flavor is a serious problem for the dairy industry because of the severity of the taste deterioration noticed and because of the speed by which the phenomenon develops. Packaging materials are essential to avoid this particular deterioration of milk.

An active $\mathrm{O}_{2}$-binding inner layer in the PET could not remove the relatively large quantity of oxygen present in the bottles. The UV filter did not completely exclude the wavelengths detrimental to riboflavin. Accordingly, photo-degradation of the milk could occur. This was demonstrated well by the riboflavin and vitamin A loss, the decrease in dissolved oxygen, the increase of the peroxide value and concentrations of volatile off-flavor compounds, and the sensorial changes in the illuminated milk samples. On the other hand, a UV absorber appeared to give some protection against light oxidation. But then again, this protection was not extensive enough to preserve milk longer from light-induced off-flavor than milk packed in transparent PET bottles. On the other hand, an adequate light barrier, which did not transmit any wavelength of the spectrum, was apparently sufficient to avoid the lightinduced oxidation. Hence, this type of PET bottle is a suitable package for the storage of UHT semi-skimmed milk at room temperature during some months.

\section{ACKNOWLEDGMENTS}

This research was made possible thanks to the support of Amcor PET Packaging, Belgium. The technical assistance of the Department of Animal Product Quality was greatly appreciated.

\section{REFERENCES}

Allen, C., and O. W. Parks. 1979. Photodegradation of riboflavin in milks exposed to fluorescent light. J. Dairy Sci. 62:1377-1379.

Barcarolo, R., C. Tutta, and P. Casson. 1996. Aroma compounds. Pages 1015-1049 in Handbook of Food Analysis. Vol. 1. Physical Characterization and Nutrient Analysis. L. M. L. Nollet, ed. Dekker, New York, NY.

Barrefors, P., K. Granelli, L.-A. Appelqvist, and L. Bjoerck. 1995. Chemical characterization of raw milk samples with and without oxidative off-flavor. J. Dairy Sci. 78:2691-2699.

Bekbölet, M. 1990. Light effects on food. J. Food Prot. 53:430-440.

Borle, F., R. Sieber, and J. O. Bosset. 2001. Photo-oxidation and photoprotection of foods, with particular reference to dairy products: An update of a review article (1993-2000). Sci. Aliments 21:571-590.

Bosset, J. O., P. U. Gallmann, and R. Sieber. 1994. Influence of light transmittance of packaging materials on the shelf-life of milk and dairy products: A review. Pages 222-268 in Food Packaging and Preservation. Mathlouthi, Blackie Academic \& Prof., London, United Kingdom.

Brubacher, G., W. Müller-Mulot, and D. A. T. Southgate. 1986. Vitamin $\mathrm{B}_{2}$ (riboflavin) in foodstuffs: HPLC method. Pages 119128 in Methods for the Determination of Vitamins in Food. G. Brubacher, W. Müller-Mulot, and D. A. T. Southgate, ed. Elsevier Applied Science Publishers, London, UK.

Chapman, K. W., L. J. Whited, and K. J. Boor. 2002. Sensory threshold of light-oxidized flavor defects in milk. J. Food Sci. 67:2770-2773.

Cladman, W., S. Scheffer, N. Goodrich, and M. W. Griffiths. 1998. Shelf-life of milk packaged in plastic containers with and without treatment to reduce light transmission. Int. Dairy J. 8:629-636.

Cooperman, J. M., and R. Lopez. 1991. Riboflavin. Pages 283-310 in Handbook of Vitamins. L. J. Machelin, ed. Dekker, New York, NY.

deMan, J. M. 1980. Light-induced destruction of vitamin A in milk. J. Dairy Sci. 64:2031-2032.

Fanelli, A. J., J. V. Burlew, and M. K. Gabriel. 1985. Protection of milk packaged in high-density polyethylene against photodegradation by fluorescent light. J. Food Prot. 45:112-117.

IDF Standard 1C. 1987. Milk. Determination of fat content. Gravimetric method. (Reference method Röse-Gottlieb). International Dairy Federation, Brussels, Belgium.

IDF Standard 74A. 1991. Anhydrous milk fat. Determination of the peroxide value. International Dairy Federation, Brussels, Belgium.

IDF Standard 142. 1990. Dried skimmed milk. Determination of vitamin A content (colorimetric and HPLC methods). International Dairy Federation, Brussels, Belgium.

IDF Standard 265. 1991. Determination of free fatty acids in milk and milk products. International Dairy Federation, Brussels, Belgium.

International Life Sciences Institute. 2000. Packaging materials. 1. Polyethylene terephthalate (PET) for food packaging applications. ILSI Europe Packaging Material Task Force, Brussels, Belgium.

Jung, M. Y., S. H. Yoon, H. O. Lee, and D. B. Min. 1998. Singlet oxygen and ascorbic acid effects on dimethyl disulfide and offflavor in skim milk exposed to light. J. Food Sci. 63:408-412.

King, R. L. 1962. Oxidation of milk fat globule membrane material. I. Thiobarbituric acid reaction as a measure of oxidized flavor in milk and model systems. J. Dairy Sci. 45:1165-1171.

Kirk, R. S., and R. Sawyer. 1991. Vitamin $B_{2}$ in flour. Pages 244245 in Pearson's Composition and Analysis of Foods. Vol. 9. R. S. Kirk and R. Sawyer, ed. Longman Scientific \& Technical, New York, NY.

Lee, K. H., M. Y. Jung, and S. Y. Kim. 1998. Effects of ascorbic acid on the light-induced riboflavin degradation and color changes in milks. J. Agric. Food Chem. 46:407-410.

Marsili, R. T. 1999. Comparison of solid phase micro-extraction and dynamic headspace method for the gas chromatographic-mass 
spectrometric analysis of light-induced lipid oxidation products in milk. J. Chrom. Sci. 37:17-23.

Mehta, R. S., and R. Bassette. 1979. Volatile compounds in UHTsterilized milk during fluorescent light exposure and storage in the dark. J. Food Prot. 42:256-258.

Min, D. B., and J. M. Boff. 2002. Chemistry and reaction of singlet oxygen in foods. Compr. Rev. Food Sci. Food Safety 1:58-72.

Mottar, J. 1986. The usefulness of co-extruded high-density polyethylene for packaging UHT milk. Milchwissenschaft 41:573-577.

Moyssiadi, R., A. Badeka, E. Kondyli, T. Vakirtzi, I. Savvaidis, and M. G. Kontominas. 2004. Effect of light transmittance and oxygen permeability of various packaging materials on keeping quality of low fat pasteurized milk: Chemical and sensorial aspects. Int. Dairy J. 14:429-436.

Parolari, G. 1996. Sensory evaluation techniques. Pages 163-196 in Handbook of Food Analysis. Vol. 1. Physical Characterization and Nutrient Analysis. L. M. L. Nollet, ed. Dekker, New York, NY.

Rysstad, G., A. Ebbesen, and J. Eggestad. 1998. Sensory and chemical quality of UHT-milk stored in paperboard cartons with different oxygen and light barriers. Food Add. Cont. 15:112-122.

Saidi, B., and J. J. Warthesen. 1995. Effect of heat and homogenization on riboflavin photolysis in milk. Int. Dairy J. 5:635-645.

Sidwell, C. G., H. Salwin, M. Benca, and J. H. Mitchell. 1954. The use of thiobarbituric acid as a measure of fat oxidation. J. AOCS 31:603-606.

Toba, T., S. Adachi, and I. Arai. 1980. Sunlight and sodium hypochlorite-induced color changes in milk. J. Dairy Sci. 63:1796-1801.

Van Aardt, M., S. E. Duncan, J. E. Marcy, T. E. Long, and C. R. Hackney. 2001. Effectiveness of poly(ethylene terephtalate) and high-density polyethylene in protection of milk flavor. J. Dairy Sci. 84:1341-1347. 